\title{
La dimensión social de la bioarqueología. Propuesta de trabajo para una investigación que incluye restos óseos humanos en Argentina
}

(a) RMA

\author{
The social dimension of bioarchaology. Proposed work for an \\ investigation including human bones in Argentina \\ *Pamela García Laborde, **María Eugenia Conforti y ***Ricardo \\ Anibal Guichón
}

Antropología Biológica

\begin{abstract}
*CONICET-Laboratorio de Ecología Evolutiva Humana (LEEH), NEIPHPA-UNCPBA Subsede Quequén. pamelagl1981@hotmail.com

${ }^{*}$ CONICET, Instituto de Investigaciones Arqueológicas y Paleontológicas del Cuaternario Pampeano (INCUAPA), PATRIMONIA, UNCPBA Facultad de Ciencias Sociales, Olavarría. meconfort@soc.unicen.edu.ar ***CONICET-Laboratorio de Ecología Evolutiva Humana (LEEH)-NEIPHPA-UNCPBA Subsede Quequén. guichon2012@gmail.com
\end{abstract}

\begin{abstract}
Resumen
La relación de los investigadores y su producción con la comunidad en general y principalmente con los pueblos originarios, plantea un grado de complejidad que no parece gestionarse ni desde la Bioarqueología ni desde la Arqueología Pública, por separado. El objetivo general de este trabajo es contribuir a la discusión sobre posibles estrategias que amplien nuestras prácticas profesionales promoviendo nuevas tramas de relaciones que articulen y reconfiguren a ambos enfoques en nuestro país. Para explorar el mencionado abordaje se presenta el caso de la Misión Salesiana Nuestra Señora de La Candelaria, ubicada en la costa Norte de Tierra del Fuego. En este sentido, la Misión Salesiana se convierte en un escenario propicio, para explorar dicha articulación y al mismo tiempo dar cuenta de que cada caso está atravesado por su historia y particularidades locales. Quizás renunciar a la autoridad absoluta para hablar del pasado constituya una de las claves para lograr transformar la disciplina, haciéndola más democrática y multivocal, a la vez que humanizarla en pos de incorporar otros aspecto y niveles de análisis más allá de las perspectivas tradicionales del trabajo científico.
\end{abstract}

Palabras clave: restos óseos humanos; Misión Salesiana; restitución; Selk’nam; Tierra del Fuego

\begin{abstract}
The relationship between researchers and society in general, but particularly between the former and native american populations sets a degree of complexity that cannot be tackle neither through the fields of Bioarchaeolgy or Public Archaeology separately. The general objective of this work is to contribute to the discussion on possible strategies that might broaden our professional practices by promoting new networks of relationships that articulate and reconfigure both fields in our country. To explore this approach, we present the case of the Salesian Mission Nuestra Señora de La Candelaria, located on the north of Tierra del Fuego. In this sense, the Salesian Mission becomes an appropiate stage to explore this articulation, while at the same time recognizing that each case is traversed by its history and local peculiarities. Perhaps renouncing absolute authority to speak of the past is one of the keys to transforming the discipline, making it more democratic and multivocal, as well as humanizing it in order to incorporate other aspects and levels of analysis beyond the traditional perspectives of the scientific work.
\end{abstract}

Keywords: human remains; Salesian Mission; restitution; Selk'nam; Tierra del Fuego

La relación entre los arqueólogos y pueblos originarios fue modificándose en el último siglo. Los avances a nivel legal, tales como por ejemplo el reconocimiento de los indígenas como sujetos de derecho, son aspectos importantes que redefinen dichas relaciones. Así mismo, se han incorporado valoraciones superadoras de los impactos negativos que el colonialismo académico (en términos generales) promovió durante mucho tiempo, a través del discurso hegemónico, donde los indios se habían extinguido, negando el pasado prehispánico como parte de la historia nacional (Galimberti 2010; Hernández Llosas et al. 2010; Jofré y Molina Otarola 2009). En la actualidad, y en relación con la actividad de investigación, el proceso de reivindicación y reconocimiento indígena está dando lugar a experiencias de articulación. Se trata de espacios nuevos con potencialidades, los cuales no están exentos de tensiones y ajustes. La reconfiguración de las formas tradicionales de investigación arqueológica 
tiende a incluir otros compromisos e involucramiento con los problemas y contextos sociales. El asesoramiento, acompañamiento y colaboración a las comunidades, generan mecanismos que tienden a facilitar, por ejemplo, las restituciones. Este es el desafío que los arqueólogos debemos enfrentar, no podemos cambiar el pasado pero si aprender de los errores y poner en práctica una arqueología ética y no colonialista, lo que algunos autores denominan reparación histórica indígena (Curtoni y Chaparro 2011; Liebmann 2008).

En este contexto, la Bioarqueología brinda las herramientas teóricas y metodológicas para poder analizar e interpretar los restos óseos humanos y acceder al conocimiento del estilo de vida de la población de la cual provienen. Cabe señalar que en general la formación disciplinar en bioarqueología en relación con las comunidades originarias se ha focalizado especialmente en el abordaje de aspectos legales de las restituciones. Entendiendo que la problemática de las interacciones entre comunidades originarias y científicas no se restringe meramente a lo legal planteamos lo que podría denominarse un área de vacancia. En este sentido, se están consolidando otros ámbitos de discusión entre ellos aquí nos interesa focalizar en algunas articulaciones posibles con la Arqueología Pública. La relación de los investigadores y su producción con la comunidad en general y principalmente con los pueblos originarios, plantea un grado de complejidad que no parece gestionarse ni desde la Bioarqueología ni desde la Arqueología Pública, por separado. En este sentido, este trabajo presenta una propuesta de interacción de ambos campos surgida a partir de un caso particular que permite explorar posibles fortalezas de una perspectiva integradora.

En una investigación arqueológica, el registro bioarqueológico representa una importante fuente de información para la comprensión del cambio biocultural resultante de la colonización (Larsen et al. 2001). Pero actualmente, los aspectos éticos, legales y sociales constituyen desafíos constantes a la vez que grandes oportunidades para los arqueólogos (Buikstra y Beck 2006; Grauer 2012) a los fines de establecer otras formas de interacción con los actuales representantes de comunidades originarias, de antiguos pobladores locales e incluso para los diversos grupos sociales (considerados de interés) involucrados. En este sentido, el abordaje bioarqueológico articulado con la Arqueología Pública, constituye una posibilidad que permite contextualizar socialmente a la investigación arqueológica y abordar la temática de manera integral (Ascherson 2000; Funari 2004; Salerno 2013; García Laborde 2017).

Para explorar el mencionado abordaje se presenta el caso de la Misión Salesiana Nuestra Señora de La Candelaria, ubicada en la costa Norte de Tierra del Fuego (Figura 1). Cabe aclarar que en la ciudad de Río Grande, desde 1990 la Comunidad Indígena Selk'nam
(Ona) revitaliza su identidad indígena y reivindica los derechos preexistentes y existentes sobre su territorio, cultura y cosmovisión. Esta comunidad formalizó su organización y registró su personería jurídica, con el nombre de Comunidad Rafaela Ishton, en el Instituto Nacional de Asuntos Indígenas, conforme a las leyes nacionales y provinciales. Cuenta con la particularidad de poseer territorio propio en la cabecera del Lago Fagnano, ya que en 1998, la provincia de Tierra del Fuego adjudicó al Pueblo Selk'nam 36.000 hectáreas de tierras comunitarias. En la actualidad parte de la comunidad habita dicho territorio mientras que otros miembros residen en las ciudades de Río Grande, Tolhuin y Ushuaia, esto da un marco de heterogeneidad al interior de la comunidad, lo cual plantea una situación compleja y desafíos para su abordaje. Esta área es investigada desde el año 2006 por el grupo de investigación Núcleo de Estudios Interdisciplinarios sobre Poblaciones Humanas de Patagonia Austral (NEIPHPA ${ }^{1}$ ) dirigido por uno de los autores (Ricardo A. Guichón), abocados principalmente al estudio del contacto interétnico en Patagonia Austral durante los siglos XIX y XX. Además de contar con los permisos oficiales para realizar las excavaciones en el cementerio de la Misión Salesiana, el equipo informó a las comunidades antes de comenzar a trabajar. Las reuniones entre el grupo de investigación y miembros de la comunidad Selk'nam, entre ellos el presidente, tenían el objetivo de ponerlos en conocimiento de las líneas de investigación, pero también para generar un diálogo oportuno en el que se explicitaran posturas e intereses de ambos grupos. Lo surgido de una manera intuitiva resultó particular y novedoso. Se pasó de una práctica profesional que de alguna forma naturalizaba e invisibilizaba a otra

1 Dependiente de la Facultada de Ciencias Sociales de la Universidad Nacional del Centro de la Provincia de Buenos Aires.

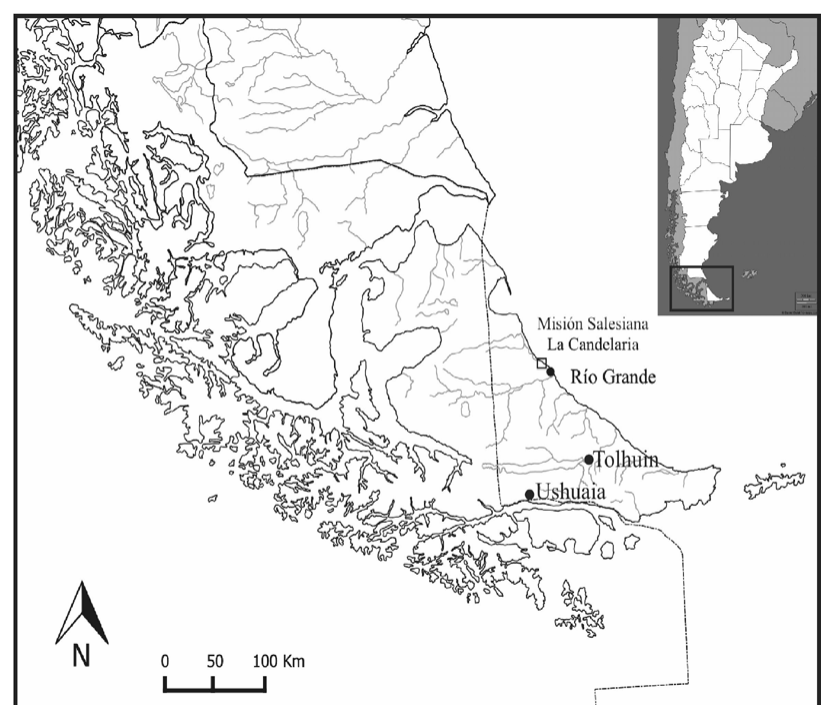

Figura 1: Ubicación de la Misión Salesiana y ubicación de las ciudades de Río Grande, Tolhuin y Ushuaia

Figure 1: Location of the Salesian Mission and location of the cities of Rio Grande, Tolhuin and Ushuaia 
donde los miembros de la comunidad comenzaban a ser tenidos en cuenta (Guichón et al. 2015). Es importante resaltar que a pesar de no contar con un protocolo consensuado, el procedimiento realizado por el equipo en el año 2006, constituye al menos un antecedente de lo que hoy se está planteando en el marco de la Ley 25.517, como "proceso de consulta previa" (Guichón et al. 2015).

En este sentido, la Misión Salesiana se convierte en un escenario propicio, para explorar la articulación de los enfoques antes mencionados, al mismo tiempo que da cuenta de que cada caso está siempre atravesado por su historia y particularidades locales. Estas interacciones constituyen una plataforma que pretende aportar otras formas de pensar los procesos de construcción de protocolos previos, el destino de los cuerpos y el uso del conocimiento generado en las investigaciones, a la vez que permita considerar también el posible manejo de los recursos para su preservación y posterior puesta en valor del patrimonio.

Por ello, el objetivo general de este artículo es contribuir a la discusión sobre posibles estrategias que amplíen nuestras prácticas profesionales promoviendo nuevas tramas de relaciones que vinculen y reconfiguren a la bioarqueología y la Arqueología Pública en nuestro país.

\section{El caso de la Misión Salesiana}

Tierra del Fuego, al igual que el resto del continente, tuvo los primeros contactos con los europeos en el siglo XVI, pero estos fueron esporádicos y breves. Fue recién a partir del siglo XIX cuando las relaciones interétnicas ganaron intensidad volviéndose sostenidas, cotidianas y de gran impacto en las poblaciones locales (Belza 1975; Borrero 2001; Casali 2011; Fugassa y Guichón 2004; Martinic 1973). La isla, se encontraba en plena consolidación nacional de los Estados argentino y chileno, caracterizada por la producción ganadera, las exploraciones militares y la explotación aurífera (Casali 2011). En dicho contexto social se instala en 1893 la Misión Salesiana Nuestra Señora de la Candelaria, en las cercanías de la actual ciudad de Río Grande (Argentina). Su objetivo, según sus convicciones, era evangelizar y "proteger a los nativos". Al cuarto año de funcionamiento ya contaban con más de 350 indígenas, pero un incendio los obligó a trasladarse a su emplazamiento definitivo (Beauvoir [1915] 2005), sobre la costa marina próxima al Cabo Domingo, a $12 \mathrm{Km}$ de la actual ciudad de Río Grande (Figura 2). Para el año 1926, la misión contaba con pocos nativos sobrevivientes y luego fue transformada en Escuela Agrotécnica, la cual subsiste hasta el presente. El cementerio de la antigua misión, se encuentra cruzando la ruta 3, hacia el mar, a un kilómetro aproximadamente. En el mismo fueron inhumados tanto los religiosos como también indígenas y antiguos pobladores de las estancias que había a los alrededores de la misión, ya que era el único cementerio de la zona hasta 1848, año en que deja de funcionar. En 1983, fueron declaradas Monumento Histórico Nacional, las estructuras originales que aún permanecen en pie: la capilla, la casa de los salesianos y el taller de hilado. Posteriormente (1999) se le suma el cementerio a dicha declaración, además en el año 2001, la provincia de Tierra del Fuego los declara de interés cultural y arqueológico.

Los trabajos en la Misión Salesiana comenzaron de forma sistemática en el año 2006, desde una perspectiva multidisciplinar. Se centran en el estudio de los cambios culturales y biológicos introducidos por la misión en
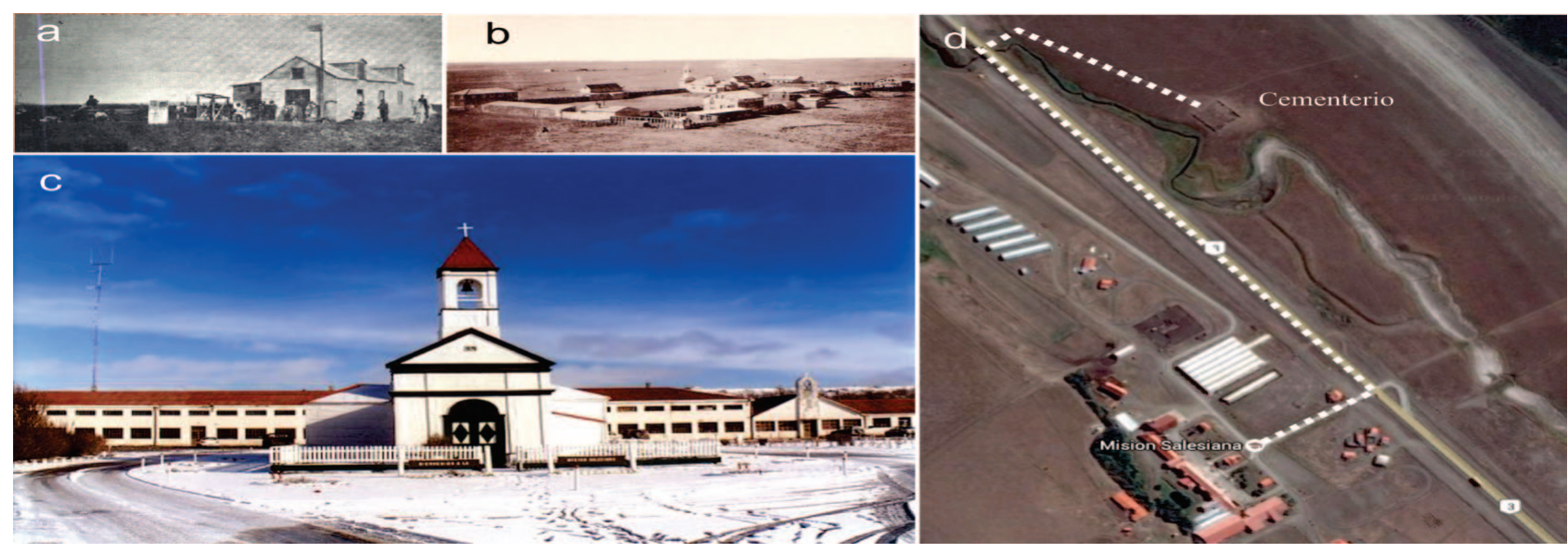

Figura 2: a) Primer asentamiento de la Misión Salesiana (Fuente: Misioneros Salesianos 1915:67). b) Ubicación definitiva con las construcciones realizadas a principio del siglo XX. c) Una imagen de la misión en la actualidad con la escuela Agrotécnica en el fondo. d) Imagen satelital donde se observa la misión y el cementerio de la misma, la línea punteada marca la distancia entre uno y otro (1 km aproximadamente)

Figure 2: a) First settlement of the Salesian Mission (Source: Salesian Missionaries 1915: 67). B) Definitive location with the constructions realized at the beginning of century XX.C) An image of the mission currently with the Agrotechnic school in the background. D) Satellite image where the mission is observed and the cemetery of the same, the dotted line marks the distance between one and another (approximately $1 \mathrm{~km}$ ) 
los individuos nativos que la habitaron. Concretamente se analizaron, desde una perspectiva historeográfica, las fuentes escritas tanto de los misioneros de Don Bosco como de las hermanas de María Auxiliadora, preservadas en el Museo Histórico y de Ciencias Naturales Monseñor Fagnano de la Misión Salesiana (Casali et al. 2006, 2009ayb; Casali 2011, 2013). Desde un enfoque bioarqueológico se estudiaron los restos óseos, recuperados en el cementerio de la misión, de forma macroscópica, radiológica y tomográfica, como parte de los trabajos paleopatológicos (García Laborde et al. 2010; García Laborde 2011, 2017; Suby et al. 2013), además de realizar con ellos estudios moleculares de ADN e isotopos estables (Motti et al. 2013, 2015, 2016; Guichón et al. 2014; García Laborde et al. 2014; Valenzuela et al. 2015). A su vez fueron recolectadas muestras de sedimentos adyacentes a los cuerpos para análisis paleoparasitológicos y palepalinológicos. A partir de la arqueología histórica se analizaron las transformaciones ocurridas en el cementerio desde su creación hasta la actualidad, se estudiaron los cambios en las prácticas mortuorias de los Selk'nam (García Laborde et al. 2011; Salerno y Guichón 2015; Salerno et al. 2016). Desde este mismo enfoque, se analizó a la misión como un espacio de frontera, en el que tuvieron lugar el contacto interétnico, la negociación y la resistencia de religiosos y nativos (Martucci et al. 2016; Martucci 2016). Así mismo las técnicas de modelado 3D están permitiendo generar aproximaciones virtuales de todo el cementerio (Salerno et al. 2016).

De manera simultánea, se realizaron tareas junto a miembros de la comunidad Selk'nam que permitieron conocer algunos de sus intereses y preocupaciones, lo cual fue redefiniendo la agenda de trabajo hasta el punto de cuestionar y replantear la manera de realizar nuestra labor profesional como arqueólogos. Durante los primeros años (a partir del 2006) las reuniones consistían en contar los trabajos realizados hasta el momento por parte del equipo, mientras que algunos de los descendientes comentaban las actividades que llevan a cabo para dar a conocer su cultura. Los años en los que no se realizaron campañas arqueológicas también se organizaron viajes de algunos de los miembros del equipo para continuar con las reuniones y no perder el contacto. Recién a partir del año 2011 se comenzaron a realizar trabajos en conjuntos, como por ejemplo la construcción de un poster que valora el trabajo entre investigadores y comunidades y la colaboración en una presentación en el "Encuentro Taller de Pueblos Originarios y Pueblos Migrantes" (ver García Laborde 2017). Durante la campaña arqueológica de 2013 y 2014 todos los días hubo encuentros con los distintos grupos de la comunidad Selk'nam (en Tolhuin, Río Grande y Ushuaia), en los que se discutían temas variados relacionados al regreso de los cuerpos y la devolución de resultados de la investigación, donde fue cobrando cada vez más importancia, la generación de espacios de diálogo. Esos años permitieron generar una presentación en conjunto en el IV Taller de Discusión sobre Restitución de Restos Humanos (Guichón et al. 2014), cuyos resultados fueron publicados en la Revista Argentina de Antropología Biológica (Guichón et al. 2015), además la comunidad participó de las tareas de excavación (2014) y el equipo, estuvo presente en una ceremonia relacionada con las "Jornadas de la Paz y Dignidad". Cabe destacar que durante estos años el equipo contó con el acompañamiento de dos miembros de la comunidad Mapuche Tehuelche "LofFemMapu" de Puerto Santa Cruz, con la cual en el marco de otro proyecto parte del equipo viene trabajando desde el año 2004. Esto constituyó un intercambio de experiencias, principalmente en relación a restituciones y resguardo de restos óseos de sus antepasados (Nahuelquir et al. 2015).

\section{Articulación de enfoques teórico/metodológicos}

La Bioarqueología busca comprender las relaciones dinámicas existentes entre las poblaciones humanas, la cultura y el ambiente, enfatizando en la necesidad de establecer la condición biológica y cultural de la sociedad, en las que el estudio de restos óseos humanos es fundamental (Bush 1991; Larsen 1984, 1997, 2000). Las investigaciones estuvieron dirigidas, principalmente, al entendimiento de la evolución de las enfermedades y el impacto de los cambios sociales y culturales sobre la salud de las poblaciones humanas (Buikstra y Cook 1980; Cohen y Armelagos 1984; Goodman y Armelagos 1989; Goodman et al. 1988; Larsen 1984, 1997). El análisis de restos óseos trae aparejado cuestiones sociales involucradas en la recuperación, estudio y restitución de los mismos. Atenderlo implica un vínculo con la sociedad y principalmente con pueblos originarios. En estos escenarios es posible reconocer tensiones entre diferentes miradas que focalizan una variedad de situaciones y aspectos. Por ejemplo, desde una perspectiva lineal es posible sugerir una disciplina tradicional (siglos XIX y $X X)$, donde dicho vinculo, poseía una connotación negativa, la noción de primitivo, salvaje y extinto. A esta le seguiría un remplazo en la última parte del siglo $X X$ y principios del XXI asociada a un mayor involucramiento de la arqueología en la sociedad. En este sentido, hace más de 30 años se viene gestando y desarrollando una subdisciplina de la arqueología, denominada Arqueología Pública, que aborda fundamentalmente los problemas que atañen a la arqueología cuando se involucra en la sociedad, tanto en los conflictos económicos, en las luchas políticas como en las cuestiones éticas (Ascherson 2000). Sus inicios se asociaron al manejo y la gestión de recursos culturales, luego a discutir las responsabilidades sociales y políticas de los arqueólogos, cuestionando además la legitimidad de las investigaciones que generan visiones del pasado nacional invisibilizando la diversidad cultural (Gnecco 2009; Salerno 2013). En la actualidad da cuenta de enfoques y modos diversos de abordar los vínculos entre arqueología y sociedad, apunta al reconocimiento del "otro" de forma positiva, es decir, reconociendo sus 
derechos e intereses (Bonnin 2015).

En este sentido, se considera que no puede disociarse un enfoque de otro, por el contrario se los propone como complementarios. Los trabajos bioarqueológicos con restos óseos humanos constituyen escenarios complejos y en particular, en contextos donde existen comunidades originarias. La práctica arqueológica debe superar la dicotomía investigación-gestión, garantizando la compatibilidad entre demandas y la producción de conocimiento nuevo (Criado Boado 1996). Se trata de procesos que involucran actividades en tres momentos: previo a las excavaciones y recuperaciones de restos óseos; durante el análisis de los mismos y a posteriori, finalizadas las investigaciones. Estas actividades están atravesadas por cuestiones legales, éticas, idiosincráticas de cada caso, por las iniciativas y voluntades del investigador y de los otros actores sociales involucrados, entendiendo que no hay una única forma de realizar este proceso, sino tantas como casos existentes y miradas posibles.

En la actualidad, nuevas perspectivas están conviviendo, tensionando y solapándose con la disciplina tradicional. Las concepciones de la ciencia asociada a un público pasivo están siendo cuestionadas. Estas nuevas perspectivas interpelan a la ciencia y a los científicos con nuevas formas de involucramiento (Conforti 2013). En este sentido, no deslindar la acción profesional arqueológica de su marco social habilita a que las investigaciones, y por sobre todo aquellas que involucran restos humanos, puedan implicarse con los intereses y agendas de los grupos de descendientes de las comunidades originarias vinculadas. Esto habilita nuevas configuraciones de vínculos que parten de un reconocimiento de la existencia y valoración de ambas partes, así como de sus dinámicas de encuentros y tensiones. A la hora de hacer el trabajo arqueológico, estos nuevos escenarios invitan a repensar las preguntas de investigación teniendo en cuenta las situaciones particulares y los contextos sociales. Como plantea Liebmann "el trabajo arqueológico no se lleva a cabo en un vacío social o cultural" (Liebmann 2008: 8). Las cuestiones políticas, las relaciones de poder, los eventos de discriminación, los derechos humanos, no son temas ajenos a nuestras prácticas científicas y podrían dejar de ser sólo teoría para adentrarse en las prácticas reales.

En un contexto de reivindicación y reclamo por los derechos indígenas, como el actual, las investigaciones arqueológicas que incluyen restos óseos humanos requieren de nuevas herramientas conceptuales y metodológicas que articulen la investigación y la gestión. Así se podrán abordar los aspectos sociales vinculados con los protocolos previos de consentimiento para llevar adelante las investigaciones y las excavaciones, como también la restitución de los cuerpos ancestrales y la puesta en valor del patrimonio que estos representan. De esta manera, la arqueología se vuelve una práctica inserta e implicada en un determinado contexto social y político, donde las necesidades, problemas e intereses de la sociedad en general y de las comunidades originarias en particular no son tema de otra área (Ayala Rocabado 2005; Endere y Ayala Rocabado 2012; Galimberti 2010; Hernández Llosas et al. 2010; Jofré y Molina Otarola 2010).

\section{Propuesta de trabajo para abordar la dimensión social en una investigación que incluya restos óseos humanos}

La Misión Salesiana es pertinente para abordar las múltiples variables de la dimensión social del trabajo bioarqueológico. En este sentido, la propuesta aquí desarrollada consiste en aplicar una Matríz FODA que permite analizar las Fortalezas, Oportunidades, Debilidades y Amenazas del caso. Esto permite, a posteriori, y en función de sus resultados, proponer una Plataforma de Trabajo que contempla tres ejes centrales: Realizado, En Proceso y Pendiente.

La Misión Salesiana es pertinente para abordar las múltiples variables de la dimensión social del trabajo bioarqueológico. En este sentido, la propuesta aquí desarrollada consiste en aplicar una Matríz FODA que permite analizar las Fortalezas, Oportunidades, Debilidades y Amenazas del caso. Esto permite, a posteriori, y en función de sus resultados, proponer una Plataforma de Trabajo que contempla tres ejes centrales: Realizado, En Proceso y Pendiente.

Cabe destacar que la utilización del FODA constituye una estrategia de sistematización y síntesis de resultados de la investigación que pudo potenciar la interpretación y el análisis del caso. Es decir, es un recurso que se manejó en la etapa reflexiva del mismo, en equipo, a partir del trabajo interdisciplinario llevado adelante por los bioantropologos y la comunicadora social (autores de este trabajo).

\section{Análisis FODA aplicado al caso de la Misión Salesiana: FORTALEZAS:}

$\checkmark \quad$ Existencia actual de la quinta generación de los Selk'nam que vivieron en la misión;

$\checkmark \quad$ El conjunto de estructuras originales que conformaban la Misión Salesiana fue declarado "Monumento Histórico Nacional"; a nivel provincial y de interés cultural y arqueológico, lo que constituye un patrimonio de interés público y científico a nivel local, provincial y nacional;

$\checkmark \quad$ Conservación de fuentes escritas de la época de su funcionamiento;

$\checkmark \quad$ Posee diez años de investigaciones científicas, que incluyen el análisis de los cuerpos recuperados del cementerio de la misión;

$\checkmark \quad$ Buena relación, diálogo y respeto mutuo entre los miembros de las comunidades y el grupo de investigadores, construida y consolidada a lo largo de 
los años;

$\checkmark \quad$ Posee un Museo Histórico y Regional;

$\checkmark \quad$ El lugar se convirtió en Escuela Agrotécnica, muy prestigiada a nivel regional, en él se realiza producción y comercialización de productos agrotécnicos;

$\checkmark \quad$ Constituye un área con potencial para interpretación, educación e investigación;

$\checkmark \quad$ Es un lugar promocionado en todas las páginas de internet turísticas de la zona y también una oferta en agencias de turismo (tanto de la ciudad de Río Grande como en toda la provincia) debido a que es el principal atractivo de la ciudad de Río Grande, por ello confluye un gran número de visitantes al lugar.

$\checkmark \quad$ Por último, la misión es elegida como lugar religioso propicio para la celebración de ceremonias de bautismos y casamientos.

A los aspectos internos mencionados, se le suman ventajas externas denominadas OPORTUNIDADES, entre ellas se destacan:

$\checkmark \quad$ Tanto el Área Municipal de Turismo como la Dirección Provincial de Museos y Patrimonio Cultural manifiestan interés público por acompañar planes de manejo;

$\checkmark \quad$ Coyuntura política y social que promueve la puesta en valor del patrimonio;

$\checkmark \quad$ El lugar posee fácil y rápida accesibilidad porque su ubicación se encuentra en la ruta nacional $\mathrm{N}^{\circ} 3$, paso obligatorio (por tierra) entre Chile y Argentina, y entre el continente y la isla;

$\checkmark \quad$ Existe en la provincia un incremento del turismo nacional e internacional, favorecido por el tipo de cambio monetario.

En cuanto a los aspectos negativos, se mencionan como DEBILIDADES:

$\checkmark \quad$ Escasos espacios de diálogo entre las autoridades salesianas y la escuela con la comunidad Selk'nam actual;

$\checkmark \quad$ La comunidad Rafaela Ishton se encuentra divida en grupos, principalmente los que viven en Río Grande y los que lo hacen en la reserva de Tolhuin;

$\checkmark \quad$ El cementerio no se encuentra en buen estado de conservación;

$\checkmark \quad$ Ausencia de un centro de interpretación en el que participen los grupos de interés;

$\checkmark \quad$ Por último, el grupo de investigación arqueológica no radica en la ciudad y la distancia se ha convertido en un aspecto importante.

En otro orden se ubican las AMENAZAS, principalmente se observa:

$\checkmark \quad$ Ausencia de acuerdos, en relación a la responsabilidad por la conservación del cementerio de la misión;

Las autoridades políticas y de la misión, cambian finalizados sus mandatos, lo cual atenta contra la posibilidad de generar acuerdos con cierto grado de estabilidad.

En esta propuesta se considera al análisis FODA como una herramienta que permite conocer algunas de las principales características de la misión para la construcción de un diagnóstico de situación. Un aspecto que enriquece el caso, a la vez que lo reviste de complejidad, es la cantidad de grupos de interés disimiles que rodean la misión. Esto plantea un desafío para las investigaciones y gestiones a realizar.

Los diez años de interacción junto a la comunidad Selk'nam fueron interpelando críticamente los intentos de abordajes lineales y simplistas que en nuestras primeras aproximaciones ingenuamente pensamos. En la práctica se generaron múltiples interacciones como consecuencia de la aparición año tras año de nuevos actores y escenarios (Guichón 2016). Los cambios en los intereses de los grupos involucrados (incluidos los científicos) fueron parte de la dinámica que, interpretamos, nos caracterizó.

Si bien desde el inicio de las investigaciones hubo contactos con miembros de la comunidad Selk'nam, recién a partir de los últimos años se formaron vínculos con toda la complejidad que ellos involucran. Esto es crucial para entender que cualquier trabajo que se pretenda articular en conjunto entre arqueólogos y comunidades, requiere muchos años de relaciones para generar espacios de confianza. En los primeros trabajos de campo se destinaban dos o tres tardes (luego de las excavaciones) para reuniones con la comunidad. Esta situación se revirtió en los últimos dos últimos años, ya que todos los días de la campaña hubo diferentes reuniones o actividades con la comunidad, así como también viajes específicos para hablar con ellos sin excavación de por medio (García Laborde 2017). Esto resultó un cambio en la planificación del trabajo de campo para el equipo. Dichos encuentros son lo que desde esta nueva perspectiva que estamos construyendo ayudaron a profundizar los vínculos, extremadamente necesarios, para lograr cualquier trabajo con y desde la sociedad. Sin embargo esto no excluye, como ya fue mencionado, que se transiten espacios de tensión y desencuentro.

Luego del diagnóstico, repensamos nuestra práctica en términos de una Plataforma de Trabajo, entendiendo como plataforma a una superficie que sirve de apoyo o base, no se trata de una receta con instrucciones a seguir, donde un cambio no permite alcanzar los resultados, por el contario se trata de una guía flexible que puede atender imprevistos o dificultades, dando lugar a modificaciones. Es necesario destacar que no deben dejarse de lado las particularidades de "lo local" en temas vinculados a problemas y realidades sociales. Esta plataforma plantea un "entramado multidimensional de redes" que por su dinamismo permite transformarse y reconfigurarse (Najmanovich 2007). Dicho dinamismo es lo que permite su aplicación en escenarios complejos como la misión. Se consideraron siete etapas, teniendo en cuenta los actores involucrados en cada una de ellas: 
1. Pre-excavación;

2. Excavación;

3. Análisis óseos;

4. Guarda transitoria;

5. Restitución;

6. Destino final de los restos óseos;

7. Devolución de resultados y puesta en valor del patrimonio.

Cabe aclarar que aunque este encuadre, se presenta enumerado, no estructura las etapas de forma lineal, por el contrario, en cada una de ellas se contempla un feedback, lo que constituye un diseño flexible que permite cambios en función de las necesidades e intereses de los grupos involucrados. En este sentido, es posible considerar que tanto la Bioarqueología como la Arqueología Pública son enfoques que aportan miradas y herramientas, con distintas formas de involucramiento, en cada

Tabla 1: Etapas de investigación y aportes de cada disciplina

Table 1: Stages of research and contributions of each discipline

\begin{tabular}{|c|c|c|}
\hline APORTES BIOARQUEOLOGÍA & $\begin{array}{c}\text { ETAPAS } \\
\text { INVESTIGACIÓN } \\
\text { QUE INVOLUCRA } \\
\text { RESTOS HUMANOS }\end{array}$ & APORTES ARQUEOLOGÍA PÚBLICA \\
\hline $\begin{array}{c}\text { El diseño de preguntas de } \\
\text { investigación. Por qué vamos a } \\
\text { hacer o intervenir en una } \\
\text { situación o lugar (de dónde } \\
\text { partimos), para qué y cómo } \\
\text { vamos hacerlo. }\end{array}$ & Pre- excavación & $\begin{array}{l}\text { Consulta hasta la participación en los } \\
\text { diseños de investigación (Protocolo de } \\
\text { consentimiento previo, libre e informado). }\end{array}$ \\
\hline $\begin{array}{l}\text { Especialistas de varias disciplinas } \\
\text { para la recolección de mayor } \\
\text { cantidad de datos. Focalización } \\
\text { en diferentes líneas de evidencias. }\end{array}$ & Excavación & $\begin{array}{l}\text { Recuperación respetuosa con la } \\
\text { participación activa o acompañamiento de } \\
\text { descendientes. }\end{array}$ \\
\hline $\begin{array}{l}\text { Herramientas metodológicas para } \\
\text { la obtención del dato y cruce de } \\
\text { evidencias. Análisis específicos en } \\
\text { lugares particulares y generando } \\
\text { posibles interpretaciones desde } \\
\text { sus perspectivas. }\end{array}$ & Análisis óseos & $\begin{array}{l}\text { Priorizar estudios no destructivos, consultas } \\
\text { sobre la utilización de técnicas destructivas. } \\
\text { Consulta hasta la participación en la } \\
\text { recuperación, análisis e interpretación de las } \\
\text { diferentes líneas de evidencia. Incluir } \\
\text { interrogantes que provienen de la } \\
\text { comunidad y atienden a sus intereses }\end{array}$ \\
\hline--- & Guarda transitoria & $\begin{array}{l}\text { Consulta hasta participación en las } \\
\text { decisiones y acciones vinculadas a las } \\
\text { condiciones de conservación de restos } \\
\text { humanos. A partir de lo anterior mejorar las } \\
\text { condiciones en los laboratorios como en los } \\
\text { museos. Trabajar con los descendientes la } \\
\text { cogestión y custodia de los reservorios. }\end{array}$ \\
\hline \multirow[t]{4}{*}{$\begin{array}{l}\text { Legislaciones que deben ser } \\
\text { conocidas y consideradas durante } \\
\text { todo el proceso de intervención. }\end{array}$} & Restitución & $\begin{array}{c}\text { Promover nuevas formas de involucramiento } \\
\text { y acompañamiento por parte de los } \\
\text { investigadores que ayuden a las } \\
\text { comunidades originarias a transitar los } \\
\text { procesos de regreso y restitución de los } \\
\text { restos. }\end{array}$ \\
\hline & $\begin{array}{l}\text { Destino final de los } \\
\text { restos }\end{array}$ & $\begin{array}{c}\text { Colaborar en que los restos puedan llegar a } \\
\text { sus descendientes y atender a que dicho } \\
\text { proceso respete los deseos e intereses de las } \\
\text { comunidades. }\end{array}$ \\
\hline & $\begin{array}{l}\text { Devolución de } \\
\text { resultados }\end{array}$ & $\begin{array}{c}\text { Los restos están acompañados con la } \\
\text { respectiva información que se generó } \\
\text { durante las investigaciones. Generación de } \\
\text { espacios de diálogo con miembros de las } \\
\text { comunidades interesadas, orientados a la } \\
\text { consulta hasta participación en las } \\
\text { decisiones sobre la comunicación pública de } \\
\text { los resultados. }\end{array}$ \\
\hline & $\begin{array}{c}\text { Puesta en valor del } \\
\text { Patrimonio }\end{array}$ & $\begin{array}{l}\text { Generación de ámbitos de diálogo } \\
\text { orientados a la consulta hasta participación } \\
\text { en las decisiones sobre el cuidado y posibles } \\
\text { dinámicas de gestión de las localidades, } \\
\text { sitios, o restos estudiados. Gestionar diseños } \\
\text { participativos, donde todos los grupos de } \\
\text { interés serán parte de una mesa de diálogo } \\
\text { desde el inicio. }\end{array}$ \\
\hline
\end{tabular}

etapa. Por un lado, la Bioarqueología se encuentra más comprometida con las tres primeras etapas y luego su aporte se restringe a cuestiones legales, principalmente. Por su parte, la Arqueología Pública genera instrumentos para afrontar de manera comunitaria y participativa aquellas cuestiones relacionadas con lo que ocurre contextualmente al análisis de los restos óseos (Tabla 1). Cabe aclarar que no se hablaría aquí de "un antes" y "un después", sino de un permanente transcurrir de las investigaciones desde una mirada amplia e integral.

Esta plataforma fue construida en función de tres ejes principales del Trabajo, aplicados al caso de la Misión Salesiana:

- Trabajo Realizado,

- Trabajo en Proceso,

- Trabajo Pendiente.

Existen antecedentes del caso que presentan avances de las etapas 1, 2 y 3 de la plataforma, es decir el Trabajo Realizado, concretamente análisis de los restos óseos orientados a estudios sobre salud, dieta, nutrición, estilo de vida, genética, practicas mortuorias, de la población Selk'nam de momentos previos y posteriores a la llegada de los europeos (García Laborde et al. 2010, 2011, 2014; García Laborde 2011, 2017; Guichón et al. 2014, 2015; Motti et al. 2013, 2015, 2016; Salerno y Guichón 2015; Salerno et al. 2016; Suby et al. 2013; Valenzuela et al. 2015).

A continuación, se abordan las etapas siguientes: Trabajo en Proceso y Trabajo Pendiente. Cabe destacar que en su elaboración se hizo hincapié en el ¿Cómo?, atendiendo la idiosincrasia local derivada del FODA (y de la experiencia de trabajo junto a la comunidad, desarrollada durante un lapso de diez años).

\section{Trabajos en Proceso}

4. Guarda transitoria y acondicionamiento de reservorios: Atendiendo a la necesidad expresada por los miembros de la comunidad, solicitando que sus ancestros no sean tratados como objetos (es decir, parte integrante de colecciones al igual que las piezas de los museos), desde el equipo se piensan en acciones que puedan en alguna medida colaborar a mejorar algunas condiciones entendiendo que se trata solo de una primera etapa. En este sentido, surge la necesidad de llevar a cabo un acondicionamiento de los espacios donde se alojaban los restos óseos en las instituciones del área de trabajo. De allí la importancia de que los cuerpos tengan un lugar separado y especial (dentro de los museos), cuya denominación no sea "depósito" y que contemple condiciones acordes a un trato respetuoso que surja de consensos. Además del compromiso profesional adoptado a partir del Código Deontológico de la AABA (2007), el cual plantea el compromiso de "velar por la conservación de los restos óseos". En este sentido, 
se acordó la generación de espacios de resguardo transitorio a los que se denominó "reservorio de restos humanos". Ubicado en un espacio aislado, implicó que los cuerpos reciban un acondicionamiento físico y embalaje, respetando las condiciones de conservación. Este tipo de reservorio fue concretado en forma cogestionada con las comunidades originarias locales en la ciudad de Puerto Santa Cruz por primera vez, (Nahuelquir et al. 2015). Las mismas características se le imprimieron al reservorio del Laboratorio Ecología Evolutiva Humana (LEEH) de Quequén. Allí se encuentran los cuerpos recuperados del cementerio de la misión. Posteriormente, se entendió la necesidad de extender esta primera etapa a la provincia de Tierra del Fuego, en el Museo Salesiano de Río Grande en Ushuaia (Museo del Fin del Mundo) y por último, en el Museo Municipal Virginia Choquintel de Río Grande (Figura 3). En todos ellos, ante la imposibilidad de poseer una habitación exclusiva para el resguardo de los restos óseos, se seleccionaron espacios dentro de los depósitos libres de humedad y a temperatura estable. En ellos se buscó la manera de generar una separación con las colecciones. Luego de realizado el acondicionamiento físico del lugar, se trabajó con los restos óseos. Se realizó una limpieza de los mismos, un informe básico que incluye inventarios, determinación de sexo y edad, y análisis general macroscópico. Por último, se modificó su embalaje y rotulación de acuerdo con condiciones de preservación y la utilización de materiales libres de ácido (Figura 3).

En simultáneo, se construyó una base de datos que contiene toda la información que existía previamente en las instituciones y la generada al momento del

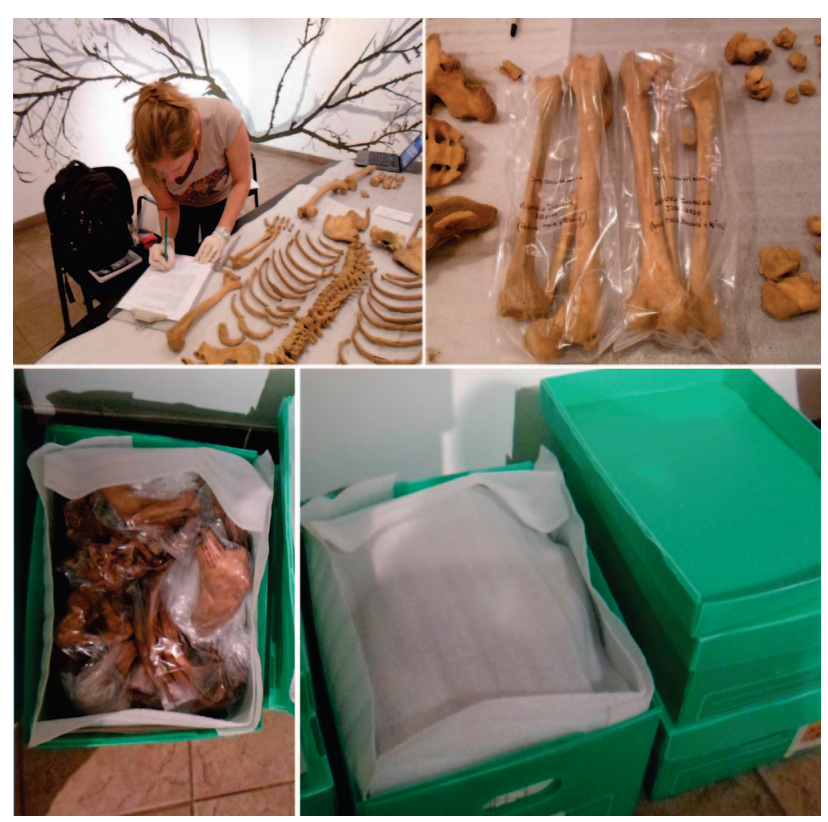

Figura 3: Acondicionamiento de restos óseos realizados en el Museo Municipal Virginia Choquintel de Río Grande

Figure 3: Conditioning of bone remains made at the Virginia Choquintel Municipal Museum in Rio Grande acondicionamiento. Se enfatizó la importancia de generar un registro documental que no fuera museológico ni estuviese orientado a los investigadores, sino que generara información que acompañara a los cuerpos. La misma se presenta en formato digital e impreso, para que los museos cuente con la información, ya sea en casos de restituciones o de ingresos a un Reservorio Transitorio Co-gestionado (Nahuelquir et al. 2015). Se buscó plasmar en este registro información variada como por ejemplo, el número de cuerpos (completos o incompletos) dentro del reservorio, la cantidad de hombres, mujeres y niños existentes, si están todos los huesos de cada persona, la presencia de otro material asociado, el lugar donde fueron recuperados, si se realizaron estudios sobre los restos óseos, de qué época son y si hay publicaciones realizadas. En la búsqueda de dar un paso más, se comenzó a considerar que la información sobre cada cuerpo constituía una suerte de "documento de identidad" de los cuerpos (Guichón et al. 2015). Al mismo tiempo este tipo de tareas permite colaborar con las instituciones, sobre todo aquellas municipales, que muchas veces no cuentan con personal calificado para estos trabajos.

\section{Trabajos Pendientes}

Este eje se constituye de dos momentos diferentes: La restitución de los cuerpos y devolución de resultados por un lado, y por otro, la puesta en valor del patrimonio, en este caso del cementerio de la misión.

\section{Restitución, 6. destino final de los restos óseos y 7.} devolución de resultados:

En la actualidad y a nivel nacional, un tema de suma importancia es la restitución de los restos óseos humanos, que involucra cuestiones políticas, legales, éticas y sobre todo identitarias. Cuando se trata de restituciones, no sólo se trabaja en cuándo y dónde sino también a quién y qué es lo que sucederá a posteriori. En relación a ello es crucial entender que las identidades se construyen, se expresan y se transforman en relación a las condiciones sociales concretas que caracterizan una situación histórica dada (Jones 1997 y 1999 en Buscaglia 2011). Comprender además, la naturaleza bidireccional o multidireccional del proceso en el cual las culturas pueden transformarse en algo nuevo, crear nuevas identidades a través de la transculturación, la etnogénesis, la criollización o hibridización (Buscaglia 2011). En este contexto, la identidad del científico también se modifica y se complejiza. Actualmente, los descendientes tienen sus propias prácticas mortuorias, diferente a la de los Selk'nam (que habitaron previo a la instalación de la misión) y diferente a las realizadas en la misión, por lo tanto las decisiones tomadas hoy son propias de esta nueva cultura que se fue transformando con el tiempo, no obstante son tan válidas como cualquier otra.

La ley Nacional 25.517, hace hincapié en que los restos óseos que se encuentren en museos o en colecciones públicas o privadas, deberán ser puestos a disposición 
de las comunidades que lo reclamen. Si bien dicha ley fue sancionada en el año 2001, fue reglamentada con el decreto 701, nueve años después. Además, tal decreto establece que el Instituto Nacional de Asuntos Indígenas (INAI), es el encargado de coordinar, articular y asistir en el seguimiento y estudio del cumplimiento de las directivas dispuestas en la Ley $N^{\circ}$ 25.517. Dicha reglamentación permite a las comunidades efectivizar sus reclamos, como sujetos de derecho, para lograr recuperar a sus antepasados y poder otorgarles un destino de acuerdo a sus tradiciones y costumbres.

Por su parte, en la provincia de Tierra del Fuego la adhesión a la Ley Nacional 25.517, se produce recién el 21 de Marzo del año 2013, a través de la Ley Provincial Nº 925. Sin embargo, los procesos de reclamos de la comunidad Selk'nam comenzaron en el año 2010. La comunidad Rafaela Ishton, solicita formalmente al Museo de La Plata, la restitución de restos mortales pertenecientes a su etnia, a través de la Secretaria de Relaciones Institucionales del Gobierno de Tierra del Fuego y de la Dirección de Afirmación de Derechos Indígenas del INAI (Ametrano 2015). En el año 2013 se produjo el dictamen favorable, luego de que los estudios permitieron corroborar la asignación étnica y de ratificar que la comunidad Rafaela Ishton era la única reclamante. En todo el proceso no participaron otros mediadores además de las instituciones mencionadas (Ametrano 2015).

El 19 de abril (2016) se efectivizó la primera restitución de restos óseos a la comunidad Rafaela Ishton, luego de haber pasado seis años desde la solicitud formal por parte de la comunidad. La Universidad Nacional de La Plata restituyó los restos óseos de cuatro personas, que estaban desde hace más de cien años en poder del Museo de Ciencias Naturales. Entre las cuatro personas restituidas se encuentra Seriot apodado "Capello", quien luchó contra la invasión de los colones y fue fusilado en 1897 en la estancia de Bridges, por orden del comisario Ramón Cortés. En el acto de la restitución estuvieron presente miembros de la Comunidad Selk'nam, entre ellos su presidente Ruben Maldonado, concluido el mismo partieron hacia Río Grande y de allí a Tolhuin donde se está construyendo un mausoleo para ubicar los restos óseos restituidos (Diario Full, 29/04/2016). En esta restitución no participaron parte de los grupos de la comunidad que viven en Río Grande, ni los investigadores que desarrollan trabajos en la zona, sino que la misma fue liderada y llevada a cabo íntegramente por el grupo que habita en Tolhuin.

Los cuerpos recuperados en el cementerio de la misión, se encuentran en forma transitoria en el Reservorios del Laboratorio de Ecología Evolutiva Humana. Desde el inicio de las investigaciones estuvieron en calidad de préstamo lo cual implica que, finalizadas las mismas, debían retornar a la provincia tal lo determinan los permisos de salida otorgados por Dirección Provincial de Museos y Patrimonio Cultural. Concretamente regresaran a la autoridad de aplicación de la provincia (Museo del Fin del Mundo, en Ushuaia), ésta será la que realice su restitución a la comunidad Selk'nam, en el caso de ser solicitada.

Es importante mencionar que las restituciones son un proceso atravesado por diversas cuestiones, tanto legales como culturales, donde, desde nuestra perspectiva nos interesa estar implicados. Generar espacios de guarda transitoria acorde a un tratamiento respetuoso, notificar la existencia de los mismos a los descendientes (derecho adquirido por Ley $\left.N^{\circ} 25.517\right)$, acompañar y asesorar a las comunidades y, sobre todo, respetar las decisiones acerca del destino final de los restos óseos es parte de nuestra agenda. Entendemos que dicho proceso no se resuelve con la existencia de leyes que las legitimen, se necesita además políticas institucionales y responsabilidades profesionales (de los investigadores).

Otra cuestión que surge a la hora de los reclamos es la legitimidad de los mismos, en relación a filiaciones entre los reclamantes y los restos óseos. En este punto vale la pena retomar una de las preguntas que se plantea Lazzari (2011) ¿Quién puede reclamar qué? Y aquí entran en juego dos cuestiones: la información que contienen los cuerpos que se encuentran en las instituciones y el reconocimiento de las comunidades originarias actuales. Como se observa en otros casos de restitución, principalmente las del Museo de La Plata, se poseía identificación de la persona a la cual pertenecían dichos restos óseos, concretamente Inacayal, Mariano Rosas, Damiana y Seriot (Arenas 2011; Curtoni y Chaparro 2011; Endere 2011; Lazzari 2011), y por ello, las discusiones se centraron en los reclamantes, su legitimidad, su reconocimiento por el INAI y si existía otra comunidad habilitada para su reclamo, entre otros. Sin embargo, cuando los reclamantes son comunidades reconocidas y sus reclamos son de restos óseos cuya información en la institución es incompleta, entonces la discusión apunta a la posibilidad que no sean sus antepasados. Es en este sentido que resulta central la responsabilidad de los investigadores en involucrarse con las instituciones para generar información sistemática de los restos óseos, datos que permitan facilitar estas cuestiones. Las tareas de acondicionamiento de los "reservorios" que el equipo de investigación viene realizando, son coherentes con políticas que se orientan a la búsqueda de formas de acompañamiento por parte de los científicos. Esto involucra una variedad de posicionamientos que parte de la redefinición de las relaciones entre profesionales y comunidades originarias hasta la denominada reparación histórica, la cual "se demuestra activa con hechos y homenajes que promueven la visibilidad de la cuestión indígena y contribuyen a la construcción de patrimonio, identidad y cultura en sintonía con los ideales de formación y consolidación del Estado-nación" (Curtoni y Chaparro 2011:2). Ejemplo de la necesidad de re-pensar estas cuestiones lo constituye el Taller de Discusión sobre 
Restituciones de Restos Humanos², actividad anual donde se discuten estas temáticas (realizados por investigadores y miembros de las comunidades.

En este punto, cabe mencionar que en el año 2010, Ricardo Guichón efectivizó el regreso de restos óseos a la provincia de Tierra del Fuego, se trató de los cuerpos recuperados y estudiados entre 1969 y 1970 por Anne Chapman, que se encontraban en el Reservorio del LEEH. Anne Chapman fue una antropóloga francoestadounidense conocida por sus estudios sobre los pueblos fueguinos, en especial de los Selk'nam, más de 40 años de investigación en Tierra del Fuego. Estos restos óseos fueron trasladados hasta el Museo del Fin del Mundo y colocados en el sector acondicionado para la guarda de todos los restos óseos que posee la institución, siguiendo los pasos descriptos en el apartado anterior (guarda transitoria y acondicionamiento de reservorio). Luego del regreso de los cuerpos se notificó a todos los grupos de la comunidad Selk'nam Rafaela Ishton. De esta manera se habilita a que la comunidad, en el caso que así lo decida, pueda realizar la solicitud formal de restitución a la institución. No se trata sólo de tener el derecho, sino de habilitar la capacidad de ejércelo.

La proyección del equipo estima que de manera similar, se procederá con los cuerpos recuperados del cementerio de la misión. Lo distintivo en este caso es que el grupo de investigación y las comunidades vienen tratando la temática en conjunto con el fin de facilitar el proceso, previsto para el año 2018. Como se observó en la restitución del Museo de La Plata, estos procesos involucran tensiones y complejidades. A partir de lo ocurrido, una demanda de los grupos de la comunidad Selk'nam es que todos tengan la posibilidad de participar y estar informados. Por ello, la consigna de este equipo es tratar de que todos estén presentes cuando se trata el regreso de los restos óseos. Una vez que los mismos se encuentren en la provincia de Tierra del Fuego, el equipo se comprometió a seguir acompañando a la comunidad en todos los pasos previos para efectivizar la restitución. En el caso del Museo de la Plata, una de las razones por la demora en la restitución fue la falta de acuerdo de los reclamantes en relación al destino final de los mismos (Ametrano 2015). Actualmente, no existe un consenso

\footnotetext{
2 En el país, desde el año 2011, anualmente, se organiza el Taller de Discusión sobre Restitución de Restos Humanos de Interés Arqueológico y Bioantropológico (en Buenos Aires, Mar del Plata, Olavarría, La Plata, Córdoba y Necochea-Quequén). En donde los profesionales de las áreas de arqueología, bioarqueología, antropólogos biólogos, entre otros, se reunieron para discutir y llegaron a algunas conclusiones, por ejemplo la necesidad de elaborar un protocolo profesional base, que sirva de guía para instrumentar un consentimiento libre, previo e informado (Endere et al. 2014). La importancia de respetar el derecho de participación de las comunidades en las investigaciones, ya sea permitiéndole el acceso al sitio, informándole sobre los procedimientos de excavación y estudio, además proporcionándole información acerca de los resultados de la investigación de un modo comprensible. En relación con los restos humanos se les deberá bridar un trato respetuoso en todas las instancias, es decir, durante la excavación, el traslado, el estudio y la guarda (Endere 2013).
}

entre la comunidad en relación al destino que pretenden para sus ancestros. Si bien, la mayoría plantea el regreso a tierra, no está definido el lugar físico.

Además del regreso de los restos óseos es importante remarcar que consideramos que los mismos deben contener información que los acompañe. En este sentido en todas las instituciones en las que se llevó a cabo el acondicionamiento de los reservorios, también se construyó una base de datos con información de las personas (digital e impresa). En el caso de la misión, además de esta base de datos documental, que acompañará a los cuerpos cuando regresen a la provincia, se acercó el resultado de las investigaciones en varios soportes (digital e impreso), confeccionados en un formato acorde a la comunicación pública. Asimismo, los grupos fueron informados y pudieron participar de los procesos de excavación, así como conocer las condiciones en las que se encuentran los restos óseos en el Reservorio del LEEH. En este sentido fue muy importante que durante el año 2014 el equipo recibiera la visita de uno de los grupos, momento en el que pudieron constatar las condiciones del lugar.

\section{Puesta en valor del patrimonio, en este caso del Cementerio de la misión}

Una de las últimas etapas propuesta en esta plataforma consiste en la puesta en valor del patrimonio. Principalmente porque los bienes históricos son, en términos de Ballart (1997) "la memoria histórica materializada" y adquieren su significado a través de tres instancias: el contexto sociocultural pasado que los generó; las transformaciones hasta llegar a la actualidad y el contexto sociocultural presente donde se realiza la práctica de valoración e interpretación (Criado Boado 1996). En este caso, se trata de la puesta en valor del cementerio del cual provienen los restos óseos involucrados en la presente investigación.

Cabe aclarar que no se desarrollará aquí la propuesta de puesta en valor ya que su diseño es parte de un trabajo más amplio y completo que excede este artículo ${ }^{3}$. No obstante, cabe mencionar algunas cuestiones generales que son centrales y le dan fundamento. Claramente se parte de asumir que la investigación arqueológica (o bioarqueológica para el caso que nos ocupa) es inseparable de la gestión, entonces resulta necesaria la interacción de los diversos grupos de interés (entre ellos los investigadores) con los gestores culturales (Curtoni y Endere 2003; Funari 2004; Haber 2004; Endere 2007; Ayala Rocabado 2008; Horwitz 2010; Gnecco y Ayala Rocabado 2011; Conforti 2012). Se trata de diseñar planes de manejo específicos atendiendo a un equilibrio entre los valores de los diferentes grupos de interés (Larsen 1995), para ello es necesario definir valoraciones

\footnotetext{
${ }^{3}$ La propuesta de puesta en valor para el cementerio de la Misión Salesiana, desde una gestión participativa que incluye desde un inicio la participación activa de todos los grupos de interés fue esbozada en la tesis doctoral de García Laborde (2017).
} 
y significaciones sociales de los bienes culturales apoyados en las diferentes percepciones que poseen dichos grupos. La identificación de los grupos de interés, así como también el relevamiento de sus opiniones y valoraciones resulta fundamental para proyectar acciones futuras en torno a la gestión del patrimonio arqueológico (Conforti y Mariano 2013; Mariano y Conforti 2013). Los resultados se pueden lograr y sostener en el tiempo si se garantizan espacios participativos donde arribar a consensos entre la diversidad de opiniones, deseos, percepciones, valoraciones y expectativas de los distintos grupos, a través de relaciones horizontales y la puesta en marcha de iniciativas que emerjan de los intereses de los destinatarios (Pearson y Sullivan 1995; Hall y McArthur 1996; Conforti y Mariano 2013; Garrido Arroyo y Hernández Carretero 2014). En este sentido, se recurre a la gestión participativa porque resulta un recurso valioso en tanto reconoce a los grupos interesados desde el comienzo de la planificación.

\section{Comentarios finales}

En este trabajo se presentó una propuesta metodológica para el abordaje de la dimensión social del trabajo bioarqueológico en un contexto de comunidades indígenas activas y presentes. Se trata del resultado de más de diez años de investigaciones en la Misión Salesiana Nuestra Señora de La Candelaria, en la que como profesionales fuimos construyendo junto a otros actores sociales un camino que implicó involucrarse en lo que denominamos dimensión social (compleja) de nuestras prácticas arqueológicas.

La estrategia desarrollada es pensada y formalizada a partir del sustento conceptual aportado por la Arqueología Pública, en la que se encuentran las bases para diagramar la gestión de un caso desde la articulación con la perspectiva Bioarqueológica. Se entiende que esta propuesta puede contribuir a la discusión sobre el trabajo con restos óseos humanos, y su respectivo manejo, en Argentina. En este sentido, generar esta herramienta posibilitó realizar una idea original que se adecúe a las demandas y requerimientos de la agenda arqueológica actual y que, se espera pueda trascender su aplicación al caso planteado y servir de inspiración (aportar herramientas) a otros investigadores en diversos contextos sociales.

El desafío de delinear una propuesta implica superar la instancia de una correcta aplicación de la Ley para arribar a los deseados consensos, por el contrario se trata de adentrarse en un trabajo con las comunidades que implica cuestiones muy sensibles como los complejos procesos de construcción de protocolos previos, el tratamiento sobre el destino de los restos humanos de sus antepasados y el uso de la información generada en las investigaciones. Además, permite atender al posterior manejo de los recursos para su preservación y puesta en valor del patrimonio desde una perspectiva participativa que incluya otras formas de interacción con los actuales representantes de comunidades "originarias", de antiguos pobladores locales e incluso para los diversos grupos de interés involucrados, con el fin de gestionar conflictos, potenciales y reales.

En nuestra experiencia un trabajo en conjunto entre comunidades originarias e investigadores precisa del establecimiento de muchos años de espacios de diálogo que fortalezcan la confianza y permitan llegar a acuerdos y consensos. Es así que potenciar y fortalecer los lazos comunicacionales aparece como un aspecto importante. Dar lugar al encuentro y al diálogo no es garantía de ausencia de tensiones y conflictos, sin embargo es el riego inevitable si se piensa en un trabajo en conjunto, ya sea para efectivizar la restitución de los cuerpos o coordinar acciones futuras, como la continuidad de las investigaciones, o su re-orientación hacia temas de interés común, etc. En este sentido, es importante contemplar dentro de los proyectos de investigación, el presupuesto de tiempo y dinero que serán necesarios para llevar adelante un verdadero trabajo de estas características. El presente es un momento histórico coyuntural, donde nuevas formas de llevar adelante el trabajo de investigación están emergiendo. Son necesarias políticas institucionales que presten atención y promuevan acciones tendientes al fortalecimiento de las vías de comunicación entre los investigadores y la sociedad.

En suma, revertir el proceso de invisibilidad indígena producido por el discurso hegemónico y promover acciones tendientes a una verdadera reparación histórica requiere un trabajo de articulación entre investigación y gestión, que garantice espacios participativos. Quizás renunciar a la autoridad absoluta para hablar del pasado constituya una de las claves para lograr transformar la disciplina, haciéndola más democrática y multivocal, a la vez que humanizarla en pos de incorporar otros aspecto y niveles de análisis más allá de las perspectivas tradicionales del trabajo científico.

Necochea, 8 Julio 2017

\section{Agradecimientos}

A nuestros colegas del Núcleo de Estudios Interdisciplinarios sobre Poblaciones Humanas de Patagonia Austral Luciano Valenzuela, Marilina Martucci, Josefina Motti, Manuel D'Angelo del Campo, Romina Casali y Melisa Salerno-. A nuestros compañeros del equipo en Santa Cruz, especialmente a Isabel Cruz (UNPA), Sebastián Muñoz. Este trabajo es también el resultado de una nueva forma de hacer-pensar la manera de hacer ciencia que aprendemos juntos con Sergio Nahuelquir, Carlos Huilinao (Comunidad Lof Fem Mapu); Margarita Maldonado, Brenda Vilte; Antonella Guevara, Mirta y María Salamanca; Cristian Pantoja; Walter Barria, Rubén Maldonado (Comunidad Selk'nam Rafaela Ishton) y la Hermana 
Ana María Fernández (Orden de María Auxiliadora). Las autoridades municipales de Río Grande (Tierra del Fuego) y de Puerto Santa Cruz (Santa Cruz) y Parques Nacionales (Parque Nacional Monte León) nos ayudaron de diferentes formas. Las autoridades salesianas tanto a nivel nacional como local de Río Grande, facilitaron diferentes aspectos de este trabajo durante años. Al Centro de Antiguos Pobladores de Río Grande, a la Escuela Agrotécnica Salesiana de Río Grande, especialmente al padre Ticó y la Dr. Bitsch por su afecto, acompañamiento y charlas (ambos ya fallecidos). Al CADIC-CONICET de Ushuaia y especialmente a Mónica Salemme, Martín Vázquez y Fernando Santiago por su ayuda y apoyo. A los directivos y personal del Museo Municipal de Río Grande y del Fin del Mundo de Ushuaia. Este trabajo contó con el apoyo a lo largo de muchos años de varios proyectos PIP/CONICET 112-200801-00996, UNPA 29/A206-1, 29/A302, 05/F723 SeCyT-UNC y UBACyT 20020090200015; Los proyectos Secyt son el 05/F723 y el 162/12; UBACYt F447; PIP 5576; PICT 01520 y PICT 0575.

\section{Bibliografía}

Ametrano, S. J. 2015. Los procesos de restitución en el Museo de La Plata. Revista Argentina de Antropología biológica, 17.

Arenas, P. 2011. Ahora Damiana es Krygi. Restitución de restos a la comunidad Aché de Ypetimi. Paraguay. Corpus. Archivos virtuales de la alteridad americana, 1(1).

Ascherson, N. 2000. Editorial. PublicArchaeology 1(1): 1-4.

Ayala Rocabado, P. 2005 Pueblos originarios y arqueología: discursos en torno al patrimonio arqueológico en San Pedro de Atacama (Segunda Región de Chile). Textos Arqueológicos. Volumen 15, Numero 2, pp. 249-263.

Ayala Rocabado, P. 2008. Políticas del Pasado: indígenas, arqueólogos y Estado en Atacama. Línea EditoriallIAM, Santiago.

Ballart Hernandez, J. 1997. El patrimonio histórico y arqueológico: valor y uso. Barcelona, Ariel.

Beauvoir, J.M. [1915] 2005.Aborígenes de la Patagonia: los Onas, tradiciones, costumbres y lengua. Ediciones Continente.

Belza, J. 1975. En la Isla del Fuego. Tomo 2. Colonización. Buenos Aires: Instituto de Investigaciones Históricas de Tierra del Fuego. 366 páginas.

Bonnin, M. 2015. La arqueología Publica en Arqgentina (Prologo). En: Fabra M, Montenegro M, Zabala ME, editores. La arqueología pública en Argentina: historias tendencias y desafíos en la construcción de un campo disciplinar. Editorial de la Universidad Nacional de Jujuy (EDIUNJU).pp: 7-12.

Borrero, L. 2001. Los Selk'am. Buenos Aires: Galerna. 142 páginas.

Buscaglia, S. 2011. "Contacto y Colonialismo. Aportes para una discusión crítica enArqueología Histórica". Anuario de Arqueología. Actas del Primer Simposio Magistral de Arqueología Colonial 3(3): 57-76. Facultad de Humanidades y Artes de la
Universidad Nacional de Rosario, Santa Fe.

Buikstra, J. E y L. A. Beck. 2006. Bioarcheology. TheContestualAnalysis of Human Remains. Boston: Elsevier.

Buikstra, J.E. y D. C. Cook. 1980. Paleopathology: An American Account. Annual Review of Anthropology 9:433-470.

Bush, E. 1991. Concepts of health and stress. En: Health in Past Societies: Biocultural Interpretations of Human Skeletal Remains in Archaeological Context, editado por E. Bush y M. Zvelebil, pp. 11-22. BAR International Series 567. Oxford.

Casali, R. 2011. "Contacto interétnico en el norte de Tierra del Fuego: la Misión Salesiana La Candelaria (Río Grande) y la salud de la población Selk'nam (1895-1931)". Facultad de Humanidades, Universidad Nacional de Mar del Plata, Argentina, 323 páginas. Tesis doctoral. Laboratorio de Ecología Evolutiva Humana (LEEH).

Casali, R. 2013 Relaciones interétnicas en Tierra del Fuego: el rol de la misión salesiana La Candelaria (1895-1912) en la resistencia Selk'nam. Revista de Estudios Marítimos y Sociales. GESMar. ISSN 1852-0669.

Casali, R., M. H. Fugassa y R. A. Guichón. 2006. Aproximación epidemiológica al proceso de contacto interétnico en el norte de Tierra del Fuego. Magallania. Vol. 34 (1):141-155. Punta Arenas, Chile. ISSN (versión on-line): 0718-2244-Casali, R. y Guichón, R. A.

Casali, R., M. H. Fugassa y R. A. Guichón. 2009a Los Selk'nam en la misión La Candelaria: aportes historiográficos al proceso de contacto en el norte de Tierra del Fuego, desde un abordaje interdisciplinario. Dora Celton, Mónica Ghirardi y Adrián Carbonetti (Coord.). Poblaciones históricas. Fuentes, métodos y líneas de investigación. Asociación Latinoamericana de Población (ALAP). CEA- CONICET-UNC. Córdoba. ISBN 978-85-62016-08-0

Casali, R., M. H. Fugassa y R. A. Guichón. 2009b Nuevos datos sobre la misión salesiana La Candelaria, Río Grande, Tierra del Fuego. Arqueología de la Patagonia: una mirada desde el último confín. Utopías. Buenos Aires. ISBN. 978-987-152-9-100.

Cohen M. N y G. J. Armelagos (Eds.). 1984. Paleopathology at the origins of agriculture. Academic Press, Orlando.

Conforti, M.E. 2012. "El rol de la comunicación pública de la arqueología y la educación no formal en la valoración social del patrimonio arqueológico en la provincia de Buenos Aires". Universidad Nacional de Quilmes, Buenos Aires, Argentina, 371 páginas. Tesis de doctorado. Instituto de investigaciones Arqueológicas y Paleontológicas del Cuaternario Pampeano (INCUAPA).

Conforti, M.E. 2013. Comunicación pública de la arqueología y análisis documental. Estudio de casos en Argentina. Chasqui. Revista Latinoamericana de Comunicación 123: 101-107

Conforti, M. E. y C. Mariano. 2013. Comunicar y gestionar el patrimonio arqueológico. Arqueología 19 (2): 347-362. Instituto de Arqueología. FFyL. UBA. 347-362.

Criado Boado, F. 1996. El futuro de la arqueología, ¿La arqueología del futuro? Trabajos de Prehistoria 53, n. ${ }^{\circ} 1:$ 15-35, España. http:// tp.revistas.csic.es

Curtoni, R. P. y M. G. Chaparro. 2011. Políticas de reparación: 
Reclamación y reentierro de restos indígenas. El caso de Gregorio Yancamil. Corpus. Archivos virtuales de la alteridad americana, 1(1).

Curtoni, P.R. y M. L. Endere. 2003. Teoría y práctica arqueológica en Sudamérica. Algunas reflexiones. En Análisis, Interpretación y Gestión en la Arqueología de Sudamérica. Editado por R. Curtoni y M. Endere, pp 7-15. Serie Teórica INCUAPA-UNICEN, Olavarría.

Endere, M. L. 2007. Management of archaeologicalsites and thepublic in Argentina. BAR International Series 1708, Oxford.

Endere, M. L. 2011 Cacique Inakayal. La primera restitución de restos humanos ordenada por ley. Corpus. Archivos virtuales de la alteridad americana, 1(1).

Endere, M. L. 2013 Recaudos legales y éticos aplicables a los profesionales que trabajan con el patrimonio arqueológico y bioantropológico. En: Temas de patrimonio cultural. Endere M., M. Chaparro y C. Mariano (eds.) 2013. UNICEN, Tandil, 116 pág. E- book. ISBN 978-950-658-343-9. pp. 13-34.

Endere, M. y P. Ayala Rocabado. 2012 Normativa legal, recaudos éticos y práctica arqueológica. Un estudio comparativo de Argentina y Chile. Chungara 44 (1): 39-58.

Endere, M.; G. Flensborg, M. González, P. Bayala, M. Chaparro, M. Berón y C. Favier Dubois. 2014. III Taller de Discusión sobre Restitución de Restos Humanos de Interés Ar-queológico y Bioantropológico. Revista del Museo de Antropología. En prensa.

Fugasa, M.H y R. A. Guichón. 2004. Transición epidemiológica en Tierra del Fuego: el contacto indirecto y las enfermedades infecciosas entre 1520 y 1850. Magallania, 32: 99-113.

Funari, P. 2004. Os antigos habitantes do Brasil. UNESP e Imprensa O9cial do Estado de São Paulo, São Paulo.

Galimberti, M. 2010. El patrimonio arqueológico y el pasado aborigen. Usos y significados del patrimonio en Catamarca. En El regreso de los muertos y las promesas del oro. Patrimonio arqueológico en conflicto, coord. por Ivana Carina Jofré, pp 6982. Encuentro/Brujas, Córdoba.

García Laborde, P. 2011. "El cementerio de la antigua Misión Salesiana "Nuestra Señora de la Candelaria" (Rio Grande, Tierra del Fuego). Bioarqueología de contacto en el siglo XIX-XX". Facultad de Ciencias Sociales, Universidad del Centro de la Provincia de Buenos Aires, Olavarría, Argentina, 142 páginas. Tesis de Licenciatura. Laboratorio de Ecología Evolutiva Humana (LEEH).

García Laborde, P. 2017 "Estado nutricional de la población Selk'nam: aproximación bioarqueológica al impacto generado por la misionalización. Misión Salesiana Nuestra Señora de La Candelaria, Tierra del Fuego (Siglos XIX-XX)".Facultad de Ciencias Sociales, Universidad del Centro de la Provincia de Buenos Aires, Olavarría, Argentina, 415 páginas. Tesis de Doctorado. Laboratorio de Ecología Evolutiva Humana (LEEH).

García Laborde, P., J. A. Suby, R. A. Guichón y R. Casali. 2010. El antiguo cementerio de la Misión de Rio Grande, Tierra del Fuego. Primeros resultados sobre patologías nutricionales-metabólicas e infecciosas. Revista Argentina de Antropología Biológica. 12 (1): 57-69.

García Laborde, P., R. Casali, M. Salerno y R. A. Guichón. 2011.
Construyendo Puentes: Evidencia documental y arqueológica del Cementerio de la Misión Salesiana "La Candelaria", Tierra del Fuego. Trabajo presentado en VIII Jornadas de Arqueología de la Patagonia. Malargüe, Mendoza, Argentina.

García Laborde P., L.O. Valenzuela y R.A. Guichón. 2014. Sinergismo entre indicadores de stress metabólico-nutricional y de enfermedades infecciosas en la misión salesiana de río grande, tierra del fuego. II Taller Nacional de Bioarqueología y Paleopatología. Organizado por el Departamento de Bioantropología y evolución. Facultad de Humanidades y Artes. Universidad Nacional de Rosario.

Garrido Arroyo, M. D. C., y A. M. Hernández Carretero. 2014. El patrimonio cultural: una propuesta de gestión participativa. Tejuelo: Didáctica de la Lengua y la Literatura. Educación, (19), 62-75.

Gnecco, C. 2009. Caminos de la Arqueología: de la violencia epistémica a la relacionalidad. Bol.Mus. Para. Emilio Goeldi, Ciencias Humanas 4 (1): 15-26.

Gnecco, C.y P. Ayala Rocabado (Editores). 2011. Indigenouspeople and archaeology in Latin American. LeftCoastPress, Walnut Creek, Estados Unidos.

Goodman, A. H., R. B. Thomas, A. C. Swedlund y G. Armelagos. 1988. Biocultural perspectives on stress in prehistoric, historical and contemporany population research. Yearbook of Physical Anthropology 31:169-202.

Goodman, A. y G. Armelagos. 1989 Infant and childhood morbidity and mortality risk in archaeological populations.World Archaeology 212: 225-243.

Grauer, A. (Editor). 2012. A CompaniontoPaleopathology. WilleyBalckwell, Malden.

Guichón, R. A. 2016. Construyendo preguntas en el camino. Comunidades originarias y científicas. Revista del museo de Antropologia de la Universidad Nacional de Córdoba. Vol. 9, Núm. 2 (2016), 27-36.

Guichón, R.A, R. Casali, P. García Laborde, L.O. Valenzuela, M. Martucci y J.M.B. Motti. 2014. Escenario epidemiológico-sanitario fueguino (1880-1930): los alcances de la tuberculosis en la población de La Candelaria y Ushuaia a partir de un examen histórico y bioarqueológico. IX Jornadas de Arqueología de la Patagonia Universidad Austral de Chile. Coyhaique.

Guichón, R.A, P. García Laborde, J.M.B. Motti, M. Martucci, R. Casali, F. Huilinao, M. Maldonado, M. Salamanca, B. Vilte, A. Guevara, C. Pantoja, M. A. Suarez, M. A. Salerno, L. O. Valenzuela, M. D. D'Angelo del Campo y P. I. Palacio. 2015. Experiencias de trabajo conjunto entre investigadores y pueblos originarios. El caso de Patagonia Austral. Revista Argentina de Antropología Biológica. Volumen 17, Número 2, Páginas 00-00. Julio-Diciembre 2015.

Haber, A. F. 2004. Hacia una arqueología de las arqueologías sudamericanas. Uniandes.

Hall, M. y McArthur, S. (Editores). 1996. Heritage Management in New Zealand and Australia. The Human Dimension. Oxford UniversityPress, Oxford.

Hernández Llosas, I., J. Ñancucheo, M. Castro y R. Quinteros. 
2010. Conocimientos compartidos para la re-significación del patrimonio arqueológico en Argentina. En El regreso de los muertos y las promesas del oro. Patrimonio arqueológico en conflicto, coord. por Ivana Carina Jofré, pp 31-68. Encuentro/ Brujas, Córdoba.

Horwitz, V. 2010. Valoración del patrimonio en la comunidad escolar de Los Antiguos (Santa Cruz, Argentina). Actas del XVII Congreso Nacional de Arqueología Argentina. Editado por R.Bárcena y H. Chiavazza, pp. 509-513. UNCuyo - CONICET, Mendoza.

Jofré, C. y R. Molina Otaola. 2009. Territorios indigenas, patrimonio y arqueologia: Un debate necesario. Revista de Antropología JANGWA PANA. Nº 8. 165-177.

Larsen, C. S. 1984 Health and disease in prehistoric Georgia: The transition to agriculture. In Cohen, M. N., and Armelagos, G. J. (eds.), Paleopathology at the Origins of Agriculture, Academic Press, Orlando, pp. 367-392.

Larsen, C. S. 1997 Bioarchaeology. Interpreting Behavior from the Human Skeleton. Cambridge University Press, Cambridge.

Larsen, C. S. 2000 Skeletons in Our Closet: Revealing Our Past Through Bioarchaeology, Cambridge University Press, Cambridge.

Larsen, C. S.; M. C. Griffin, D. L. Hutchinson, V. E. Noble, L. Norr, R. F. Pastor, C. B. Ruff, K. F. Russell, M. J. Schoeninger, M. Schultz, S. W. Simpson y M. F. Teaford. 2001. Frontiers of Contact: Bioarchaeology of Spanish Florida. Journal of World Prehistory, Vol. 15, No. 1, 2001

Larsen, K. (Editor). 1995. Nara ConferenceonAuthenticity. 1-6 November, 1994. Nara, JapanProceeding. UNESCO WorldHeritage Centre, Agency for Cultural Affairs (Japan), ICCROM, ICOMOS. Agency for Cultural Affaire, Tokio.

Lazzari, A. 2011. Reclamos, restituciones y repatriaciones de restos humanos indígenas: cuerpos muertos, identidades, cosmologías, políticas y justicia. Corpus. Archivos virtuales de la alteridad americana, 1(1).

Liebmann, M. J. 2008 Introduction: The intersections of Archaeology and postcolonial studies. En Liebmann, M. J. y U. Z. Rivzi (eds.) Archaeology and the Postcolonial Critique. Altamira Press, Lanham, New York, Toronto, Plymouth, UK. Pp. 1-20.

Mariano, C. y M. Conforti. 2013. Del registro al patrimonio, un camino con curvas cerradas. Gestión del patrimonio arqueológico y comunicación pública de la ciencia. Revista Colombiana de Antropología 49 (1): 279-300.

Martinic, M. 1973. Panorama de la colonización en Tierra del Fuego entre 1881-1900. An. del Instituto de la Patagonia, 4: 5-69.

Martucci, M. 2016. "Heterogeneidad espacial en la Misión Salesiana Nuestra Señora de la Candelaria: expresión de la identidad étnica Selk'nam durante el proceso de contacto interétnico (Río Grande, Tierra del Fuego)". Facultad de Ciencias Sociales, Universidad del Centro de la Provincia de Buenos Aires, Olavarría, Argentina, 324 páginas. Tesis de Doctorado. Laboratorio de Ecología Evolutiva Humana (LEEH).

Martucci, M., P. García Laborde y R.A. Guichón. 2016. Resultados preliminares del sitio Las Casitas 1 en un contexto de colonialidad. La Candelaria, Río Grande, Tierra del Fuego, siglos XIX y XX.
En: Arqueología de Patagonia: De mar a mar. Editor principal: Francisco Mena. Editorial: CIEP-Ñire Negro ediciones. Pp: 466-476.

Motti J.M.B., L. S. Jurado-Medina, P. García Laborde, G. Bailliet, R. A. Guichón y C. M. Bravi. 2013. Primeros Resultados De ADN Mitocondrial en Miembros De La Comunidad Selk'nam, Tierra Del Fuego, Implicancias y Perspectivas. XI Jornadas Nacionales de Antropología Biológica. Buenos Aires. Argentina.

Motti, J.M.B., K. Harkins, P. García Laborde, L. O. Valenzuela, M. Cuello, A. C. Stone, C. M. Bravi y R. A. Guichón. 2015. Develando el poblamiento humano de la Patagonia austral: aportes de los estudios de secuencias completas de ADN mitoncondrial. Libro de Resúmenes de las XII Jornadas Nacionales de Antropología Biológica. Martín Kowalewskiধ Mariana Raño - 1a edición Corrientes 2015. p. 32

Motti, J.M.B., K. Harkins, C. de la Fuente, P. García Laborde, M. Cuello, A. C. Stone, R. A. Guichón y C. M. Bravi. 2016. Filogeografía de los linajes mitocondriales del sur de Patagonia. XIV Congreso de la Asociación Latinoamericana de Antropología Biológica. Tacuarembó, Uruguay. Del 18 al 21 de Octubre 2016.

Nahuelquir S, C. Huilinao, F. Huilinao, R. A. Guichón, S. Caracoche y P. García Laborde. 2015. Trabajamos juntos. Antes y después de la ordenanza municipal de Puerto Santa Cruz 169/9. En: Fabra $\mathrm{M}$, Montenegro M, Zabala ME, editores. La arqueología pública en Argentina: historias tendencias y desafíos en la construcción de un campo disciplinar. Editorial de la Universidad Nacional de Jujuy (EDIUNJU).pp: 77-92.

Najmanovich, D. 2007. El desafío de la Complejidad: Redes, cartografías dinámicas y mundos implicados. Utopía y Praxis Latinoamericana / Año 12. № 38 (Julio-Septiembre, 2007) Pp. 71 - 82 Revista Internacional de Filosofía Iberoamericana y Teoría Social / ESA - FACES - Universidad del Zulia. Maracaibo-Venezuela.

Pearson, M. y S. Sullivan. 1995. Lookingafter heritage places. The basics of heritage planning for managers, landowners and administrators. Melbourne University Press, Melbourne.

Salerno, M., R. A. Guichón, P. García Laborde y D. Hereñú. 2016. Prácticas mortuorias, dinámicas de poder e identidad en el cementerio de la misión salesiana Nuestra Señora de la Candelaria (Río Grande, Tierra del Fuego). En: Actas de las IV Jornadas Interdisciplinarias, Territorios, Memorias e Identidades. IMICIHU, CONICET, Buenos Aires. En prensa.

Salerno, M y R. A. Guichón. 2015 Sobre la memoria y el olvido: Los difuntos Selk'nam y el cementerio de la misión salesiana Nuestra Señora de La Candelaria (Río Grande, Tierra del Fuego). Enviado a Magallania.

Salerno, V. 2013. Arqueología Pública: Reflexiones Sobre la Construcción de un Objeto de Estudio. Revista Chilena de Antropología N²7, 1er Semestre. 7-37.

Suby J.A., S. Costantino, C. Capiel, M. M. Lucarini y E. Etchepare. 2013. Exploraciones de la densidad mineral ósea y osteopenia en poblaciones humanas antiguas de Patagonia austral. Intersecciones en Antropología 14 (2013) 433-445

Valenzuela, L.O., P. García Laborde y R. A. Guichón. 2015. Transición dietaria de los Selk'nam en períodos de contacto europeo- indígena. XII Jornadas Nacionales de Antropología Biológica. Corrientes, Argentina, 22-25 Septiembre 2015. 